\title{
RESEARCH
}

Open Access

\section{Effect of duration from lingual nerve injury to undergoing microneurosurgery on improving sensory and taste functions: retrospective study}

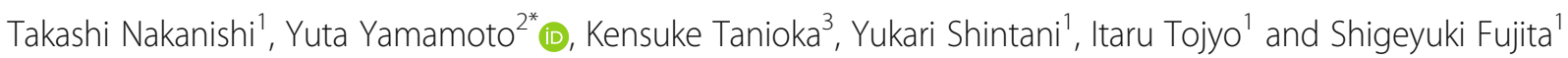

\begin{abstract}
Background: The prognosis of recovery following microneurosurgery for injured lingual nerves varies among individual cases. This study aimed to investigate if recovery ratios of sensory and taste functions are improved by the microneurosurgery within 6 months after lingual nerve injury.

Methods: We retrospectively assessed 70 patients who underwent microneurosurgery at the Wakayama Medical University Hospital for lingual nerve injuries between July 2004 and December 2016. Sensory and taste functions in lingual nerves were preoperatively evaluated using a static two-point discrimination test, an intact superficial pain/tactile sensation test, and a taste discrimination test. They were evaluated again at 12 and at 24 months postoperatively. The abundance ratio of Schwann cells in the excised traumatic neuromas was analyzed with ImageJ software following immunohistochemistry with anti S-100 $\beta$ antibody.

Results: In early cases (microneurosurgery within 6 months after the injury), recovery ratios of sensory and taste functions were not significantly different at 24 months after microneurosurgery compared with later cases (microneurosurgery more than 6 months after the injury). Meanwhile, the ratio of patients with taste recovery within 12 months after microneurosurgery was significantly decreased in late cases compared with early cases. The abundance ratio of Schwann cells in traumatic neuroma was also significantly lower in later cases.

Conclusion: Microneurosurgery more than 6 months after lingual nerve injury did not lead to decreased recovery ratio of sensory and taste functions, but it did lead to prolonged recovery of taste. This delay may be associated with a decrease in the abundance ratio of Schwann cells in traumatic neuromas.
\end{abstract}

Keywords: Duration time to surgery, Lingual nerve, Microneurosurgery, Peripheral nerve recovery, Schwann cells taste function

\footnotetext{
* Correspondence: yuta-y@wakayama-med.ac.jp

${ }^{2}$ Department of Anatomy and Cell Biology, Wakayama Medical University,

811-1 Kimiidera, Wakayama, Wakayama 641-8509, Japan

Full list of author information is available at the end of the article
} 


\section{Background}

The lingual nerves are formed by the merging of branches from the mandibular nerve with the chorda tympani, providing not only somatosensory, but also taste innervation in the mucosa of the anterior two thirds of the dorsum of the tongue [1]. They may be incidentally injured in various oral and maxillofacial surgical procedures, including lower third molar removal, submandibular gland removal, sagittal splitting of the mandibular ramus, and malignant tumor removal $[2,3]$. Such lingual nerve damage reportedly occurs in between 0.21 and $23 \%$ of cases, especially during lower third molar removal [4-7]. Although most patients with lingual nerve injury have complete recovery of their sensory functions without treatment after several weeks, between approximately 0.5 and $1 \%$ of patients either do not recover or only marginally recover $[8,9]$. In patients with permanent sensory disturbance, traumatic neuroma has been observed at the proximal stump of the injured lingual nerve [10]. These patients can have permanent sensory disorders, including disappearance of taste, anesthesia, and dysesthesia including allodynia. To treat such sensory and taste disorders, microneurosurgery is performed to remove the traumatic neuroma followed by suturing the proximal and distal edges of the lingual nerve [11]. The degree of functional sensory recovery (FSR) after microneurosurgery, however, varies between individuals.

Several retrospective studies have been performed to identify factors related to FSR over the past 30 years [12]. The duration from lingual nerve injury to the microneurosurgery has been associated with an improved ratio of sensory function in several studies [13-16]. Susarla et al. suggested that the ratio of FSR achievement was significantly higher in patients who underwent microneurosurgery within 90 days after lingual nerve injury than in patients who underwent microneurosurgery after that time [13]. Conversely, Robinson et al. reported no correlation between the duration from lingual nerve injury to surgery or in the distance in two-point discrimination (2PD) tests [17]. Focusing on taste recovery, the relationship between this duration and function recovery has not been widely reported specific to the lingual nerve. Thus, any associations between recoveries of sensory and taste functions and the duration between lingual nerve injury and microneurosurgery have not been elucidated.

Traumatic neuromas develop at the proximal end of an injured site and can be defined as "a nonneoplastic proliferation of Schwann cells and regenerating axons in an exaggerated response to nerve injury" or "an attempt by an injured nerve to regenerate" [18, 19]. Swaim et al. and Seddon et al. reported that the shape and location of the traumatic neuroma may be used to estimate the prognosis for peripheral nerve repair $[20,21]$. Raffe classified traumatic neuromas into four types according to the forms of neuroma, noting that the type could predict the treatment outcome [22]. However, any relationship between the number of Schwann cells in traumatic neuroma and function recovery in lingual nerves have not yet been examined in retrospective studies.

This study aimed to investigate if recovery ratios of sensory and taste function are improved by the microneurosurgery within 6 months after lingual nerve injury. We also measure the abundance ratio of Schwann cells in the traumatic neuroma removed from injured lingual nerve in the microneurosurgery to investigate the relationship between the duration from lingual nerve injury to microneurosurgery and the abundance ratio of Schwann cells in traumatic neuroma.

\section{Methods}

\section{Study design and patients}

This was a retrospective study. We collected observation data based on the inclusion criteria; patients underwent microneurosurgery of the lingual nerve in Wakayama Medical University Hospital between July 2004 and December 2016 for lingual nerve injury caused by third molar extraction. Patients were classified into two groups: those who underwent microneurosurgery within 6 months after lingual nerve injury (early cases) and those more than 6 months after injury (later cases). This was in accordance with previous study of lingual nerve recovery [14], because some patients with lingual nerve injury can spontaneously recover the sensory and taste function within 3 months. Collection of observational data was based on opt-out consent, and collection of traumatic neuromas and normal lingual nerves was based on written informed consent. This study was performed in accordance with the Declaration of Helsinki for medical protocols and was approved by the Wakayama Medical University Institutional Review Board (Nos. 1689 and 1698).

\section{Evaluation of lingual nerve repair}

The sensory and taste tests in the tongue were performed according to the procedures described by Fujita et al. [11]. Briefly, the criteria for achieving FSR were static $2 P D<20 \mathrm{~mm}$ and the presence of superficial pain/tactile sensation, light touch, and brush-stroke direction without overreaction. The criterion for functional taste recovery was improving at 
least one kind of taste perception compared with the results of the preoperative in taste test using Taste Disc (Sanwa Kagaku Kenkyusyo Co., Nagoya, Japan; salty: sodium chloride $1.0 \mathrm{~mol} / \mathrm{L}$, sweet: sucrose 1.0 $\mathrm{mol} / \mathrm{L}$, sour: acetic acid $0.4 \mathrm{~mol} / \mathrm{L}$, and bitter: quinine $0.1 \mathrm{~mol} / \mathrm{L}$ ).

\section{Surgical procedures}

All patients were seen and evaluated by one of the authors (S F). The microneurosurgery to repair the injured lingual nerve was performed by one (SF) of the authors, when patients met the criteria for performing the microneurosurgery. The criteria were as follows: (1) no signs of recovery during close followup for at least 3 months (2) good in general medical condition, (3) two-point discrimination (2PD) $>20$ $\mathrm{mm}$ in the affected area, (3) no sensation observed against cold $\left(0{ }^{\circ} \mathrm{C}\right)$ or hot water $\left(42{ }^{\circ} \mathrm{C}\right)$ during a temperature test in the affected area, (4) no sensation against salt, sweet, sour, or bitter observed during a taste test in the affected area, (5) no sensation against sharp touch observed during a pin-prick test in the affected area, (6) no sensation against any directions observed during a brush-stroke test in the affected area, and (7) a difference in the SemmesWeinstein monofilament test between the affected and non-affected side. Microneurosurgery procedures for lingual nerve injury were performed in all cases as previously reported [11]. Briefly, the lingual nerve was approached by an intraoral mucosal incision and lingual flap reflection, and the scar tissues around the injured site were removed. The traumatic neuroma was excised, and direct end-to-end epineural nerve sutures without tension were performed at eight or more sites around the stump using 8-0 or 9-0 nylon.

\section{Immunohistochemistry in traumatic neuroma samples}

The excised traumatic neuroma samples in the microneurosurgery were collected from 2013 onward and fixed in $10 \%$ neutral buffered formalin overnight. Thirty traumatic neuroma samples were embedded in paraffin and sliced longitudinally. Endogenous peroxidase activities were removed by incubation with $0.3 \%$ hydrogen peroxide for $1 \mathrm{~h}$. Non-specific immunoreactivities were blocked by incubation with Blocking One (Nacalai Tesque, Inc., Kyoto, Japan) for $1 \mathrm{~h}$. The sections were incubated with primary antibodies at $4{ }^{\circ} \mathrm{C}$ overnight, followed by incubation with secondary antibodies conjugated with peroxidase for $1 \mathrm{~h}$. The dilution ratio of the anti-S100 beta antibody was $1 / 1000$. Secondary antibodies were detected using 3, 3'-diaminobenzidine solution with $0.01 \%$ hydrogen peroxide, and methyl green was used for nuclear staining.

\section{Quantification of Schwann cells in traumatic neuroma samples}

Images of the tissue sections were acquired with a microscope (Eclipse E600, Nikon, Japan), and a section from approximately the middle of each specimen was selected for analysis. To determine the abundance ratio of Schwann cells, the area of immunoreactivity against anti-S100 $\beta$ antibodies was measured using ImageJ software in three fields of view from the central side of the traumatic neuroma to the peripheral side. The abundance ratio of Schwann cells in each sample was calculated as the average of the immunoreacted area against antiS100 $\beta$ antibodies per tissue area in three fields of view [23-25].

\section{Statistical analysis}

The primary outcome was the ratio difference of functional sensory or taste recovery at 12 months after microneurosurgery between early and later cases. Secondary outcomes were ratio difference of allodynia appearance at 12 months after microneurosurgery between early and later cases, ratio difference of sensory or taste function recovery at 24 months after microneurosurgery between early and later cases, differences between early and later cases of ratio of functional sensory or taste recovery within 12 months after the microneurosurgery compared with those 12 to 24 months after microneurosurgery, and the abundance ratio of Schwann cells in traumatic neuroma samples between early and later cases.

All data were statistically analyzed using JMP Pro 12 (SAS Institute Inc., NC, USA). Statistical comparisons were performed between early and later cases for FSR, functional taste recovery, and the presence of allodynia using Fisher's exact test. The distance in 2PD test and abundance ratio of Schwann cells were statistically compared between early and later cases using Student's $t$ tests. For all analyses, $P<0.05$ was considered to be statistically significant.

\section{Results}

Seventy patients underwent microneurosurgery for lingual nerve injury caused by third molar extraction between 2004 and 2016 at Wakayama Medical University and were followed up more than 12 months after the surgery (Fig. 1). No patients were excluded according to the study eligibility criteria. Finally, 70 patients (males 19, females 51; age $36.2 \pm 11.7$ years) 


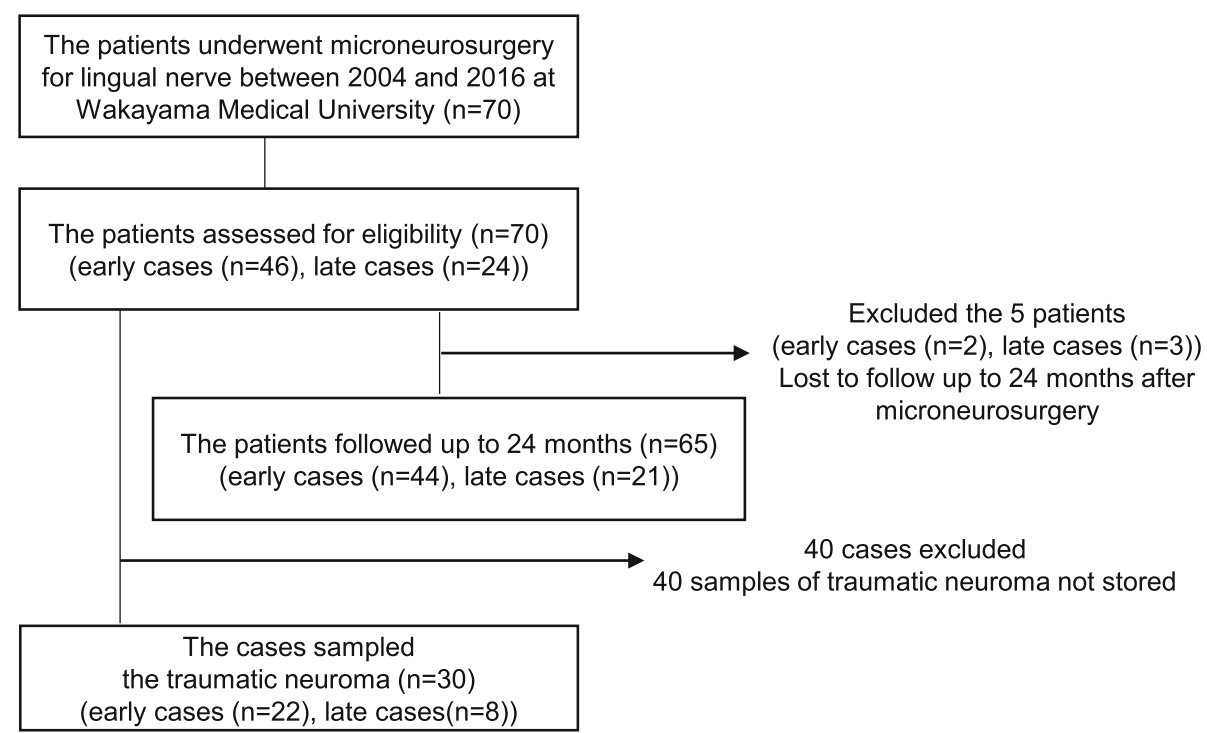

Fig. 1 Trial profile. All patients underwent microneurosurgery for lingual nerve injury caused by third molar extraction at Wakayama Medical University Hospital between 2004 and 2016. Sixty-five out of 70 patients could be followed up to 24 months. Thirty traumatic neuroma samples were analyzed using immunohistochemistry

were included. Before the surgery, 36 patients had allodynia, and the average score in $2 \mathrm{PD}$ test was $18.7 \pm 4.5$. Forty-six of the 70 patients underwent microneurosurgery within 6 months after lingual nerve injury. Table 1 shows the duration between lingual nerve injury and microneurosurgery, showing age, sex, side of injury, and neuroma-in-continuity or nerve-end neuroma in each case. Thirty-six of the 70 patients had allodynia before the microneurosurgery, 20 of whom were early cases. Forty-eight of the 70 patients were $>20 \mathrm{~mm}$ in the 2PD test. We performed sensory and taste tests for all patients at 12 months after surgery to evaluate the relationship between the ratio of FSR achievement and the duration between injury and surgery. Five out of 70 patients were lost to follow-up and excluded from analysis of the ratio difference of sensory or taste function recovery at 24 months after microneurosurgery

The 2PD tests, allodynia appearance tests, and taste discrimination tests indicated no significant difference between early and later cases at 12 months after microneurosurgery (Table 2). Furthermore, focusing on functional sensory and taste recovery, we analyzed the results of tests at 24 months after the microneurosurgery of the 65 patients who could be followed up to that point (Fig. 1). Functional sensory and taste recovery were not significantly improved in the early cases compared with later cases $(P=0.655$, $P=0.586$, Table 3 ). Meanwhile, the ratio of the patients with improving taste function in the first 12

Table 1 Patient characteristics

\begin{tabular}{llll}
\hline & Early cases & Later cases & $P$ value \\
\hline Sample size & 46 & 24 & - \\
$\begin{array}{l}\text { Mean duration from injury } \\
\text { to repair (days) }\end{array}$ & $124.7 \pm 41.2$ & $725.4 \pm 822.8$ & - \\
Age (years) & $35.5 \pm 11.9$ & $37.4 \pm 11.2$ & 0.970 \\
Female sex (\%) & 76.1 & 66.7 & 0.412 \\
Injury on right side (\%) & 58.7 & 58.3 & 0.977 \\
Neuroma-in-continuity (\%) & 54.4 & 50.0 & 0.804 \\
Allodynia appearance (\%) & 43.4 & 67.0 & 0.081 \\
2PD test (mm) & $18.9 \pm 4.3$ & $18.4 \pm 4.6$ & 0.655 \\
\hline Plus
\end{tabular}

Plus-minus values are means \pm SD. $P$ values were calculated using Student's $t$ test or Fisher's exact test. In the two-point discrimination test, 48 patients could not distinguish between two points $20 \mathrm{~mm}$ apart. The result of the two-point discrimination test in the 48 subjects was $20 \mathrm{~mm}$ 
Table 2 Comparison of early and later treatment after lingual nerve injury at 12 months after surgery

\begin{tabular}{llll}
\hline & Early cases & Later cases & $P$ value \\
\hline 2PD test $(\mathrm{mm})$ & $12.6 \pm 4.2$ & $11.1 \pm 3.7$ & 0.173 \\
Allodynia appearance & $6(13.0 \%)$ & $4(16.7 \%)$ & 0.857 \\
FSR achievement & $38(82.6 \%)$ & $18(75.0 \%)$ & 0.517 \\
Recovery of taste & $25(54.4 \%)$ & $9(37.5 \%)$ & 0.127 \\
\hline
\end{tabular}

Plus-minus values are means \pm SD. $P$ values were calculated using Student's $t$ test or Fisher's exact test. In the two-point discrimination test, four patients could not distinguish between two points $20 \mathrm{~mm}$ apart. The result of the twopoint discrimination test in the four patients was $20 \mathrm{~mm}$

months after the microneurosurgery compared to those in the following 12 months was remarkably higher in early cases than in later cases $(P=0.016$, Table 4).

To explore the factors associated with the longer time to improve taste function in later cases than early cases, we analyzed 30 samples of traumatic neuromas fixed by formalin in the immunohistochemistry using anti-S100 $\beta$ antibody to recognize Schwann cells. Twenty-two of the 30 samples were from early cases, and eight were from later cases (Fig. 1). The abundance ratios of Schwann cells in traumatic neuroma were $55.3 \pm 17.6 \%$ in the early cases and $27.9 \pm$ $5.5 \%$ in the later cases (Fig. 2). The abundance ratio was significantly lower in later cases compared with early cases $(P=0.002)$.

\section{Discussion}

In previous studies, lingual nerve recovery was associated with the duration from lingual nerve injury to microneurosurgery, but the methods of evaluation and the criteria of duration from injury to microneurosurgery varied between them (Table 5) [1316]. Functional sensory recovery is often evaluated by $2 \mathrm{PD}$ and/or Semmes-Weinstein (SW) tests, and FSR achievement is defined as proper patient sensory perception, generally evaluated by $2 \mathrm{PD}$ and allodynia appearance. FSR may therefore better reflect patient's sensory function than the results of a functional sensory test only. The patients undergoing microneurosurgery within 3 or 6 months after lingual nerve injury was defined as early case in
Table 4 Treatment period to improve sensory and taste function in early and later cases

\begin{tabular}{|c|c|c|c|c|c|}
\hline & \multicolumn{2}{|c|}{ Early cases } & \multicolumn{2}{|c|}{ Later cases } & \multirow[b]{2}{*}{$\begin{array}{l}P \\
\text { value }\end{array}$} \\
\hline & $\begin{array}{l}12 \\
\text { months }\end{array}$ & $\begin{array}{l}24 \\
\text { months }\end{array}$ & $\begin{array}{l}12 \\
\text { months }\end{array}$ & $\begin{array}{l}24 \\
\text { months }\end{array}$ & \\
\hline $\begin{array}{l}\text { FSR } \\
\text { achievement }\end{array}$ & 36 & 5 & 18 & 1 & 0.654 \\
\hline $\begin{array}{l}\text { Recovery of } \\
\text { taste }\end{array}$ & 25 & 2 & 9 & 6 & 0.016 \\
\hline
\end{tabular}

Numbers/percentages represent the number and ratio of cases. $P$ values were calculated using Fisher's exact test

previous studies (Table 5). Vincent et al. and Renton et al. indicate that some patients can spontaneously recover the sensory and taste function within 3 months [26, 27]. Thus, we perform microneurosurgery after the 3-month follow-up of the lingual nerve injury to exclude the patients who can spontaneously recover the sensory and taste function. In the current study, the patients undergoing microneurosurgery within 6 months after lingual nerve injury was defined as early case.

In this study, there were no significant differences in the ratio of achievement of FSR between early and later cases, although the ratio of allodynia appearance before microneurosurgery tended to be lower in early cases than in later cases. Susarla et al. reported that the ratio of FSR achievement was significantly high in patients who underwent surgery within 3 months of lingual nerve injury. Bagheri et al. also reported that the odds ratio of FSR achievement was significantly high in patients who underwent surgery within 6 months of lingual nerve injury (Table 6). However, reanalysis of data used by Bagheri et al. using the chi-square test resulted in a $P$ value of 0.056 , and the $95 \%$ confidence interval for the odds ratio was between -0.01 and 0.18 (Table 6). The sample size in the study of Bagheri et al. was, however, larger than that of other studies. We calculated the effect sizes of the odds ratio for FSR achievement on the duration from injury to surgery on order to adjust the sample size among the studies, and we compared the difference of odds ratio for FSR among the studies. The effect size reported by Susarla et al. was as much as double that

Table 3 Functional sensory and taste recovery in early and later cases at 24 months after surgery

\begin{tabular}{lllllll}
\hline & \multicolumn{2}{l}{ Early cases } & & \multicolumn{2}{l}{ Later Cases } & \\
\cline { 2 - 3 } & Improvement & No improvement & & Improvement & No improvement & $P$ value \\
\hline FSR achievement & $41(93.2 \%)$ & $3(6.8 \%)$ & $17(38.6 \%)$ & $19(90.5 \%)$ & $2(9.5 \%)$ & 0.655 \\
Recovery of taste & $27(61.4 \%)$ & $15(71.4 \%)$ & $6(28.6 \%)$ & 0.586 \\
\hline
\end{tabular}

Numbers/percentages represent the number or ratio of cases. $P$ values were calculated using the Fisher's exact test 

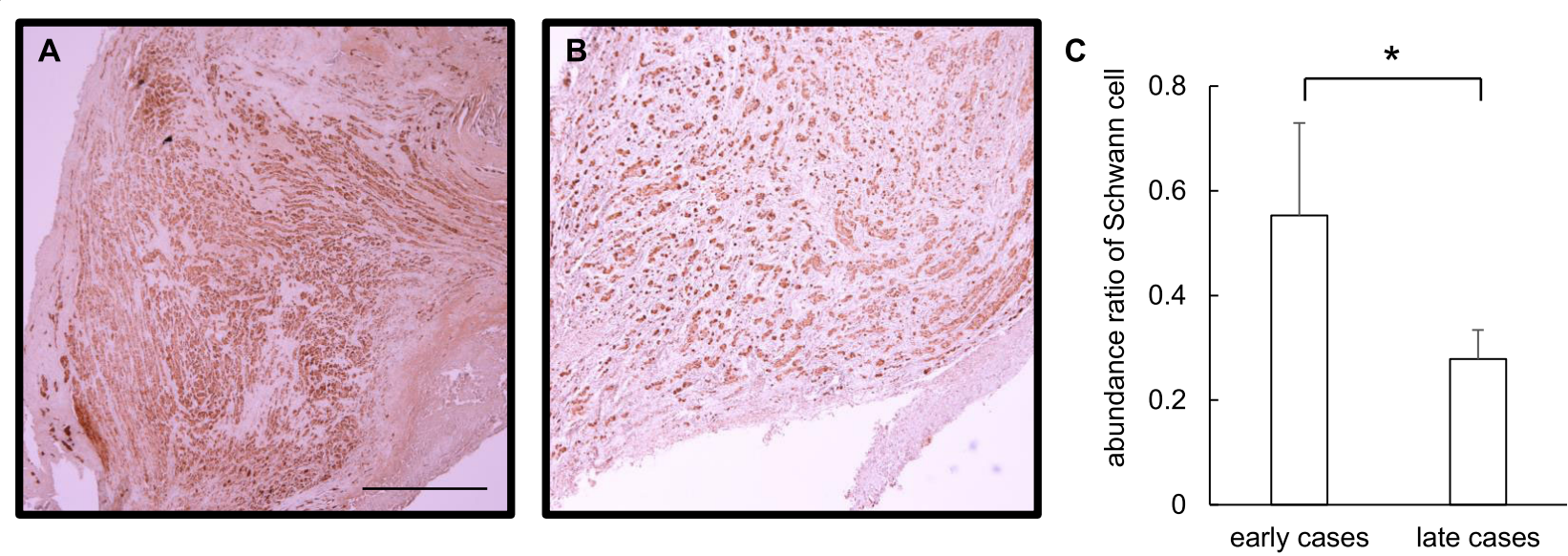

Fig. 2 Effect of duration from lingual nerve injury to the microneurosurgery on Schwann cells in traumatic neuroma. Immunohistochemistry using anti-S100 $\beta$ antibody was performed on traumatic neuroma samples from early cases (a) and later cases (b). The abundance ratio of Schwann cells was significantly lower in the traumatic neuroma samples from later cases (c). Scale bar indicates $500 \mu \mathrm{m}$. Asterisk indicates significant difference between early and later cases $(P<0.05)$

reported by both Bagheri et al. and the current study. The surgery within 6 months after lingual nerve injury may not therefore be fully associated with FSR achievement, although surgery within 3 months of the injury may have some association.

The current study did not show significant improvement of sensory or taste functions in early cases at 12 and 24 months after the microneurosurgery (Tables 2 and 3). Focusing on the patients with improving sensory and taste functions, taste function was recovered within 12 months after the microneurosurgery in almost all of the early cases. In contrast, over a year was needed for improvement of taste function in $40 \%$ of later cases whose taste function recovered (Table 4). Thus, patients who undergo microneurosurgery more than 6 months after lingual nerve injury may require more time to improved taste function compared with patients who undergo microneurosurgery within 6 months after lingual nerve injury.

Table 5 Criteria of surgery and the evaluation methods in previous studies

\begin{tabular}{lll}
\hline Author & $\begin{array}{l}\text { Criteria of period to undergo } \\
\text { surgery after lingual nerve injury }\end{array}$ & $\begin{array}{l}\text { Evaluation } \\
\text { methods }\end{array}$ \\
\hline Pogrel et al. [2] & $<3$ & Pogrel's score \\
Susarla et al. [13] & $<3$ & FSR \\
Ziccardi et al. [15] & $<6$ & 2PD, SW \\
Mozsary et al. [32] & $<6$ & FSR \\
Bagheri et al. [14] & $<6$ & MRCS \\
Robinson et al. [17] & None & 2PD \\
\hline
\end{tabular}

Traumatic neuroma occurs at the proximal end of an injured site because of differentiation and proliferation of Schwann cells [28]. Schwann cells are critical components in nerve regeneration, including promotion of axon growth and myelination in damaged peripheral nerves [29]. Hall et al. reported that the no myelination for long time in absent axon induced apoptosis in Schwann cells, and Schwann cells were disappeared [30]. In the present study, the number of Schwann cells in late cases was significantly reduced compared with early cases based on histopathological analysis. The past reports also indicated that the number of Schwann cells was therefore decreased in the traumatic neuromas owing to the delay of the microneurosurgery [31]. Thus, the reduction of Schwann cells could suppress the nerve regeneration in sensory or taste function. The differences in the duration from injury to surgery did not affect the ratio of improvement of sensory or taste disorder but affect a period to recover taste function in this study. Therefore, the delay of the microneurosurgery after the injury may need more time to recover taste function followed by decreasing the number of Schwann cells. This histological analysis to measure the number of Schwann cells in removed traumatic neuroma may predict the period to recover taste function, and further studies should validate this hypothesis.

\section{Conclusion}

Microneurosurgery within 6 months after lingual nerve injury was not associated with improvement of sensory and taste functions. However, a longer period was required to recover taste function in patients undergoing 
Table 6 Relationship between FSR achievement and the duration from injury to the microneurosurgery in our study and in past studies

\begin{tabular}{|c|c|c|c|c|c|c|c|c|}
\hline \multicolumn{2}{|l|}{ Early cases } & \multicolumn{2}{|l|}{ Later cases } & \multirow[b]{2}{*}{ Threshold months } & \multirow[b]{2}{*}{$\begin{array}{l}P \text { value, Fisher's } \\
\text { exact test }\end{array}$} & \multirow[b]{2}{*}{$\begin{array}{l}P \text { value, } \\
\text { chi-square } \\
\text { test }\end{array}$} & \multirow[b]{2}{*}{$\begin{array}{l}95 \% \mathrm{Cl}[\text { lower, } \\
\text { upper] }\end{array}$} & \multirow[b]{2}{*}{ Effect size } \\
\hline FSR achieved & Total & FSR achieved & Total & & & & & \\
\hline 38 & 46 & 18 & 24 & 6 & 0.534 & 0.659 & $-0.16,0.31$ & 0.09 \\
\hline 125 & 133 & 76 & 89 & 6 & 0.037 & 0.056 & $-0.01,0.18$ & 0.14 \\
\hline 13 & 14 & 31 & 50 & 3 & 0.047 & - & $0.07,0.54$ & 0.28 \\
\hline
\end{tabular}

Effect sizes were calculated with Fisher's exact test. $P$ value was not calculated with chi-square test in the study by Susarla et al. because the number of patients that did not achieve FSR among the early cases was less than five

microneurosurgery more than 6 months after lingual nerve injury. This may be partially associated with the decrease in Schwann cells in traumatic neuromas. Clinicians should inform patients on the possible necessity of 2 years until improvement of taste function if they undergo microneurosurgery more than 6 months after lingual nerve injury.

\section{Abbreviations}

2PD: Two-point discrimination; FSR: Functional sensory recovery; SW: Semmes-Weinstein

\section{Acknowledgements}

I would like to thank the members in the Department of Anatomy and Cell Biology and Oral and Maxillofacial Surgery at Wakayama Medical University for the technical assistance with the experiments. The study was supported by a grant from the Grant-in-Aid for Scientific Research from Japan Society for the Promotion of Science (No.15 K11318) and scholarship donation from NIPRO Medical Corporation.

We acknowledge the proofreading and editing by Benjamin Phillis at the Clinical Study Support Center at Wakayama Medical University.

\section{Authors' contributions}

TN read and wrote the manuscript. TN, SY, and IT prepared the retrospective data. KT analyzed and interpreted this data. YY revised and corrected the manuscript. YY and SF designed and wrote the entire article. All authors read and approved the final manuscript.

\section{Funding}

There is no funding related to this article.

\section{Availability of data and materials}

Please contact the author for data requests.

\section{Ethics approval and consent to participate}

This study was performed in accordance with the Declaration of Helsinki for medical protocols and was approved by the Wakayama Medical University Institutional Review Board (Nos. 1689 and 1698). General consent was given by the patients.

\section{Competing interests}

The authors declare that they have no competing interests.

\section{Author details}

'Department of Oral and Maxillofacial Surgery, Wakayama Medical University, 811-1 Kimiidera, Wakayama, Wakayama 641-8509, Japan. ${ }^{2}$ Department of Anatomy and Cell Biology, Wakayama Medical University, 811-1 Kimiidera, Wakayama, Wakayama 641-8509, Japan. ${ }^{3}$ Clinical Study Support Center, Wakayama Medical University, 811-1 Kimiidera, Wakayama, Wakayama 641-8509, Japan.
Received: 23 September 2019 Accepted: 10 December 2019

Published online: 27 December 2019

References

1. Martos-Fernandez M, de-Pablo-Garcia-Cuenca A, Bescós-Atín MS (2014) Lingual nerve injury after third molar removal: unilateral atrophy of fungiform papillae. J Clin Exp Dent; 6(2): e193-e196.

2. Pogrel MA, Renaut A, Schmidt B, Ammar A (1995) The relationship of the lingual nerve to the mandibular third molar region: an anatomic study. J Oral Maxillofac Surg 53:1178-1181

3. Behnia H, Kheradvar A, Shahrokhi M (2000) An anatomic study of the lingual nerve in the third molar region. J Oral Maxillofac Surg 58:649-651

4. Andreasen JO, Laskin DM, Petersen JK (1997) Textbook and color atlas of tooth impactions: diagnosis, treatment, prevention. Munksgaard, Copenhagen, Denmark, pp 87-126

5. Bataineh $A B$ (2001) Sensory nerve impairment following mandibular third molar surgery. J Oral Maxillofac Surg 59:1012-1017

6. Kim SY, Hu KS, Chung $H$, Kim HJ (2004) Topographic anatomy of the lingual nerve and variations in communication pattern of the mandibular nerve branches. Surg Radiol Anat 26:128-135

7. Guerrero ME, Nackaerts O, Beinsberger J, Hoer K, Schoenaers J, Jacobs R (2012) Inferior alveolar nerve sensory disturbance after impacted mandibular third molar evaluation using cone beam computed tomography and panoramic radiography: a pilot study. J Oral Maxillofac Surg 70:2264-2270

8. Kipp DP, Goldstein BH, Weiss WW (1980) Dysesthesia after mandibular third molar surgery: a retrospective study and analysis of 1,377 surgical procedures. J Am Dent Assoc 100:185-192

9. Mason DA (1988) Lingual nerve damage following lower third molar surgery. Int J Oral Maxillofac Surg 17:290-294

10. Gregg JM (1990) Studies of traumatic neuralgias in the maxillofacial region: surgical pathology and neural mechanisms. J Oral Maxillofac Surg 48:228-237

11. Fujita S, Tojyo I, Yamada M, Go Y, Matsumoto T, Kiga N (2014) Outcome following lingual nerve repair with vein graft cuff: a preliminary report. $J$ Oral Maxillofac Surg; 72: 1433.e1-7.

12. Mackinnon SE (1989) Surgical management of the peripheral nerve gap. Clin Plast Surg 16:587-603

13. Susarla SM, Kaban LB, Donoff RB, Dodson TB (2007) Does early repair of lingual nerve injuries improve functional sensory recovery? J Oral Maxillofac Surg 65:1070-1076

14. Bagheri SC, Meyer RA, Khan HA, Kuhmichel A, Steed MB (2010) Retrospective measures of microsurgical repair of 222 lingual nerve injuries. J Oral Maxillofac Surg 68:715-723

15. Ziccardi VB, Rivera L, Gomes J (2009) Comparison of lingual and inferior alveolar nerve microsurgery outcomes. Quintessence Int 40:295-301

16. Cornelius CP, Roser M, Ehrenfeld M (1997) Microneural reconstruction after iatrogenic lesions of the lingual nerve and the inferior alveolar nerve. Critical evaluation. Mund Kiefer Gesichtschir 1:213-223

17. Robinson PP, Loescher AR, Smith KG (2000) A prospective, quantitative study on the clinical outcome of lingual nerve repair. Br J Oral Maxillofac Surg 38:255-263

18. Rasmussen OC (1980) Painful traumatic neuromas in the oral cavity. Ora Surg Oral Med Oral Pathol Oral Radiol Endod 49:191-195

19. Swanson $\mathrm{HH}$ (1961) Traumatic neuromas: a review of the literature Oral Surg Oral Med Oral Pathol Oral Radiol Endod 14:317-326 
20. Seddon HJ (1965) Nerve injuries. J Univ Mich Med Center 31:4-10

21. Swaim SF (1972) Peripheral nerve surgery in the dog. J Am Vet Med Assoc 161:905-911

22. Raffe MR (1979) Compendium on Continuing Education for the Small Animal Practitioner; 1: 269-276.

23. Vora AR, Bodell SM, Loescher AR, Smith KG, Robinson PP, Boissonade FM (2007) Inflammatory cell accumulation in traumatic neuromas of the human lingual nerve. Arch Oral Biol 52:74-82

24. Vora AR, Loescher AR, Craig GT, Boissonade FM, Robinson PP (2005) A light microscopical study on the structure of traumatic neuromas of the human lingual nerve. Oral Surg Oral Med Oral Pathol Oral Radiol Endod 99:395-403

25. Bird EV, Christmas CR, Loescher AR, Smith KG, Robinson PP, Black JA, Waxman SG, Boissonade FM (2013) Correlation of Nav1. 8 and Nav1. 9 sodium channel expression with neuropathic pain in human subjects with lingual nerve neuromas. Molecular Pain 9:52-62

26. Vincent IN, Miloro M (2013) Trigeminal nerve injuries. Springer-Verlag, Berlin Heidelberg, Chicago, Illinois, USA, pp 149-166

27. Renton T, Yilmaz Z (2012) Managing iatrogenic trigeminal nerve injury: a case series and review of the literature. Int J Oral Maxillofac Surg 41:629-637

28. Kline DG, Nulsen FE (1972) The neuroma in continuity: its preoperative and operative management. Surg Clin North Am 52:1189-1209

29. Steed MB (2013) Nerve injury and regeneration. IN: Miloro M. Trigeminal Nerve Injuries. Springer-Verlag Berlin Heidelberg, Chicago, Illinois, USA; 149-166.

30. Hall S (2005) The response to injury in the peripheral nervous system. J Bone Joint Surg 87-B:1309-1319

31. Terenghi G, Calder JS, Birch R, Hall SM (1998) A morphological study of Schwann cells and axonal regeneration in chronically transected human peripheral nerves. J Hand Surg [Br] 23:583-587

32. Mozsary PG (1987) Inferior alveolar and lingual nerve injuries: regeneration or operation? J Oral Maxillofac Surg 45(3):204-286

\section{Publisher's Note}

Springer Nature remains neutral with regard to jurisdictional claims in published maps and institutional affiliations.

\section{Submit your manuscript to a SpringerOpen ${ }^{\circ}$ journal and benefit from:}

- Convenient online submission

- Rigorous peer review

- Open access: articles freely available online

- High visibility within the field

- Retaining the copyright to your article

Submit your next manuscript at $\boldsymbol{\nabla}$ springeropen.com 